\title{
Design, Simulation and Comparison of Controllers for Temperature Profile Tracking Control of a Heat Flow System
}

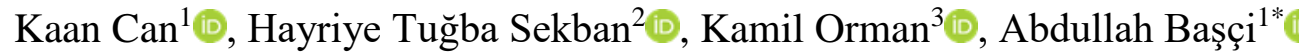 \\ ${ }^{1}$ Department of Electrical \& Electronics Engineering, Ataturk University, Erzurum Turkey \\ ${ }^{2}$ Technical Sciences Vocational School, Electronics \& Automation Department, Bayburt University, Bayburt, \\ Turkey \\ ${ }^{3}$ Department of Computer Engineering, Erzincan Binali Yıldırım University, Erzincan, Turkey
}

Geliş / Received: 08/07/2020, Kabul / Accepted: 26/08/2020

\begin{abstract}
In this paper, the design, simulation and performance comparison of the three different controllers applied to the heat flow system (HFS) are presented. First, the dynamic model of the HFS was obtained and so as to test the temperature control, sliding mode controller (SMC), adaptive sliding mode controller (ASMC) and adaptive fractional order sliding mode controller (AFOSMC) are designed and applied. To analyse the performance of the designed controllers a simulation environment is developed via the Matlab/Simulink software. The results, obtained through a simulation environment are represented by tracking error, adaptation gain, response to sudden changes, maximum overshoot, rise time and settling time and they showed that the heat flow system follows the reference temperature profile trajectory with less errors, overshoot, rise time and settling time by using the AFOSMC than the other controllers. Also, the maximum errors, rise time and settling time occurred when the sliding mode controller is used.
\end{abstract}

Keywords: Heat flow system, temperature control, adaptive control, sliding mode control, fractional-order control.

\section{Design, Simulation and Comparison of Controllers for Temperature Profile Tracking Control of a Heat Flow System}

Öz

Bu makalede, 1sı-akış sistemine uygulanan üç farklı kontrolcünün tasarımı, simülasyonu ve performans karşılaştırması sunulmuştur. İlk olarak, 1sı-akış sisteminin dinamik modeli elde edilmiş ve devamında 1sı kontrolünü gerçekleştirmek için kayan kipli kontrol (KKK), adaptif kayan kipli kontrol (AKKK) ve adaptif kesir dereceli kayan kipli kontrol (AKDKKK) yöntemleri tasarlanmış ve uygulanmıştır. Tasarlanan kontrolcülerin performansını analiz etmek için Matlab/Simulink programı aracılığıyla 1sı-akış sisteminin simülasyonu oluşturulmuş ve tasarlanan kontrolcülerin performansı analiz edilmiştir. Simülasyon ortamından elde edilen referans sıcaklık takip hatası, adaptasyon kazancı, ani değişimlere karşı kontrolcünün tepkisi, maksimum aşım, yükselme ve yerleşme zamanı gibi sonuçlar sunulmuş ve elde edilen sonuçlardan AKDKKK'nün diğer kontrolcülere göre referans sıcaklığı daha az hata ile takip ettiği, daha düşük aşım, yükselme ve yerleşme zamanına sahip olduğu gözlemlenmiştir. Ayrıca, KKK uygulandığında en yüksek referans sıcaklık takip hatası, yükselme ve yerleşme zamanına sahip olduğu gözlemlenmiştir.

Anahtar Kelimeler: Isı akış sistemi, sıcaklık kontrolü, adaptif kontrol, kayan kipli kontrol, kesir-dereceli kontrol. 


\section{Introduction}

From past to present temperature control is of great importance in industrial and engineering applications (Agrawal et al., 1987; Omatu et al., 1992; Seaman et al., 1994; Taur et al., 1995). Temperature control is used with different control methods, especially in industrial process, ambient temperature control and heat treatment for materials. The most common control tasks in temperature control applications are temperature set point control, temperature uniformity control and temperature profile tracking control. Temperature profile tracking is used to obtain time-varying temperature for the precise heat treatment of materials and the applications in batch chemical reactor. Temperature profile control has attracted attention due to various problems encountered in application in real time systems. Because it requires flexible, stable and adaptable control beyond the factors such as the testing environment and changing time constants. For a variation of reference values and expansion of the implementing period a filtering and its installation could be investigated. The identified components can provide a stable control of the model and a real test for the examined time span and periodic execution size.

In the literature, there are many applications for temperature control in various engineering fields. Some of those, Lin et al. proposed a Neural Fuzzy Inference Network (NFIN) method and applied to the control problem of the water bath temperature (Lin et al., 1999). With the proposed method, they suggested that they can cope with a changing environment or facility problem that cannot be fully addressed by conventional controllers such as the PID controller. The performance and success of NFIN in the water bath temperature-control have been demonstrated by experimental results. Petráš and Vinagre (2002), chose to control a lab object consisting of the heat solid. As a result of their work, they have shown that the system with the integerorder controller stabilises slower and has larger surplus oscillations and the use of the fractional-order controller provides better control of the real system. Juang and Chen (2003), introduced a new TSK-type recurrent neural fuzzy network (TRNFN). They applied the TRNFN for temperature control of practical water bath. Ramos et al. (2004), suggested a low-cost automated temperature controlled method that it contains the PID control method for an experimental bath. Can and Başçi (2017), applied a fractional-order PI controller (FOPI) for a real-time HFES produced by Quanser Inc. The experimental results have been realized through the three heat sensors. Also, the FOPI controller has been compared with the integer one called classical PI. The obtained results from the Quanser HFES have indicated the priority of the FOPI with respect to classical one. Ahn et al. (2008), proposed the use of a fractionalorder PID controller to allow a spatially distributed heat flow to more accurately follow a temperature profile and performed a real experimental study using the HFES of Quanser. Jain et al. (2019), proposed a two degree of freedom FOPI controller for temperature control of a HFES and the controller parameters were optimized with a meta-heuristic algorithm called the water cycle algorithm (WCA).

The SMC method is preferred in many nonlinear systems due to its useful properties such as robustness against parameter changes and insensitivity to external disturbances. Another advantage of this method is that it can change the dynamic and the closed loop behaviour of the system with the help of the 
determined sliding function (Young et al. 1999).

Adaptive control is an effective method to deal with parameter changes (Ioannou and Sun, 2012; Astrom and Wittenmark, 2013). Baek et al. (2016), proposed a new ASMC method combined with pole placement control (PPC) and time delay estimation technique and applied the proposed method to robot manipulators both simulated and experimentally. In the proposed method, the adaptation law used provided a very fast adaptation and chattering reduction, taking into account the arbitrary small circumference of the sliding manifold. Liao et al. (2018), proposed a new ASMC methodology using the boundary layer concept for a class of uncertain nonlinear systems. In the proposed method, the adaptation law has been designed to increase and decrease the sliding gain, based on the feature in which the system will be within the boundary layer.

In this paper, SMC, ASMC and AFOSMC are applied to the HFE system of Quanser for temperature profile tracking control. The simulation results showed the priority of the AFOSMC when it compared with the other controllers.

\section{Material and Methods}

\subsection{Heat flow experimental setup}

In the experimental setup shown in Figure 1; the heated air mass is transported with the aid of a fan through the channel. Inside the channel three temperature sensors are located in fixed distances (http://www.quanser.com).

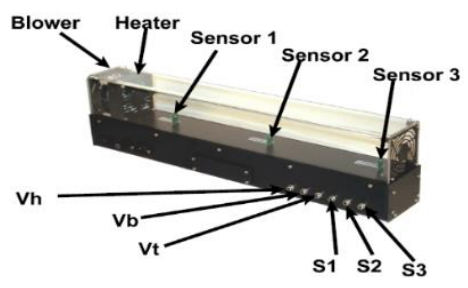

Figure 1. Heat flow experimental setup of Quanser(https://www.quanser.com /products/ heat-flow-experiment/)

It is difficult to fully express the thermodynamic model of this system. In practice, the state variables of the system can be expressed as follows.

$\dot{T}_{n}=F\left(V_{h}, V_{b}, T_{a}, x_{n}\right)$

where $T_{n}$ is temperature at sensor $n, V_{h}$ is heater voltage, $V_{b}$ is blower voltage, $T_{a}$ is ambient temperature and $x_{n}$ is distance of sensor $n$ from heater.

\subsection{System structure}

The state-space model of the heat flow system can be expressed as follows,

$\dot{T}=f(T, t)+g(T, t) u, T\left(t_{0}\right)=T_{0}$

where $T$ indicates the state of the system and also, its initial value is defined as $T_{0}, u(t) \in R$ is the control input and $f(T, t) \in R$ specifies nonlinear derivative terms. Also, $g(T, t) \in R$ represents a positive defined nonlinear function. Besides, taking into account the uncertainties in the system (Zeinali and Khajepour, 2010);

$\left.\begin{array}{l}f(T, t)=\hat{f}(T, t)+\Delta f(T, t) \\ g(T, t)=\hat{g}(T, t)+\Delta g(T, t)\end{array}\right\}$

where $\hat{f}(T, t)$ and $\hat{g}(T, t)$ are the known parts, $\Delta f(T, t)$ and $\Delta g(T, t)$ are the unknown parts of equation (2), respectively. In the light of this 
information, the equation (2) can be rewritten as given below.

$$
\dot{T}=(\hat{f}+\Delta f)+(\hat{g}+\Delta g) u(t)+d(t)
$$

where $d(t) \in \mathrm{R}$ represents the bounded external disturbances. When the equation (4) is rearranged, the following equation is obtained.

$$
\dot{T}=\hat{f}+\hat{g} u(t)+(\Delta f+\Delta g u(t)+d(t))
$$

Assumption 1. It is assumed that all uncertain elements can be lumped as in (Gutman, 1979), and the matching conditions are satisfied (Zeinali and Khajepour, 2010):

$$
\begin{aligned}
& \Delta f=\hat{g} \gamma_{1}, \Delta g=\hat{g} \gamma_{2}, d(t)=\hat{g} \gamma_{3} \\
& \gamma=\Delta f+\Delta g(u)+d(t)=\hat{g}\left(\gamma_{1}+\gamma_{2}+\gamma_{3}\right)
\end{aligned}
$$

If equation (5) is rewritten taking into account the equation (7),

$$
\dot{T}=\hat{f}+\hat{g} u(t)+\gamma
$$

where $\gamma$ represents the lumped uncertainties and its partial derivatives are bound continuously and locally uniformly in the Euclidian norm (Zeinali and Khajepour, 2010);

$$
\|\gamma(T, \dot{T}, u, t)\| \leq \delta(T, \dot{T}, u, t)<\infty
$$

where $\delta(T, \dot{T}, u, t)$ is the unknown upper bound of uncertainty norm $\|\gamma(T, \dot{T}, u, t)\|$.

\subsection{Controller design}

In this section, the proposed control metedology is presented and derived. First, the fractional-order control is introduced with a simple mathematical theory and then, SMC is expressed. After that, the adaptive control law is derived based on the fractional-order SMC.

\subsubsection{Adaptive Fractional-Order SMC design}

The fractional-order control is a kind of calculation method that it is getting more attention due to its beneficial properties such as providing more flexible and sensitive calculation with respect to integer-order calculation for differentiating of some mathematical expressions. Therefore, this method has been used especially by researchers interested in control theory. The fractional operator is represented as ${ }_{a} D_{t}^{p}$ in this paper.

${ }_{a} D_{t}^{p}= \begin{cases}\frac{d^{p}}{d t^{p}} & p>0 \\ 1 & p=0 \\ \int_{a}^{t}(d t)^{-p} & p<0\end{cases}$

where $a$ and $t$ represent lower and upper limits of the operator and, $p \in R$ is order of the operator.

Basically, in literature, two calculation theories are taken into account to calculate fractional-order differentiation that are the Grünwald-Letnikov (GL) and RiemannLouville (RL) (Vinagre et al., 2000). The mathematical expression of the GL method can be expressed (Vinagre et al., 2000);

$$
{ }_{a} D_{t}^{p} f(t)=\lim _{h \rightarrow 0} h^{-p}\left[\frac{t-a}{\sum_{j=0}^{h}}(-1)^{j}\left(\begin{array}{l}
p \\
j
\end{array}\right) f(t-j h)\right.
$$

where $\left[\frac{t-a}{h}\right]$ term represents an integer term. The RL method can be described for $n-1<p<n$

$$
{ }_{a} D_{t}^{p} f(t)=\frac{1}{\Omega(n-p)} \frac{d^{n}}{d t^{n}} \int_{a}^{t} \frac{f(\tau)}{(t-\tau)^{p-n+1}} d \tau
$$


where $\Omega($.$) is the function of gamma$ (Podlubny, 1999).

In the SMC method, the error and its derivative are used to describe a sliding surface as given in equation (14). For this nonlinear control method, the control objective is accomplished in two stages; reaching and the switching phases, respectively. In reaching phase, the control objective is to wipe the system states on sliding manifold. In switching phase, the system has an equivalent control to reach the system states to equilibrium point. During this mode, the system exhibits a neutral state against disturbances that may come from outside and are not effected by parameter uncertainties. The sliding surface $s$ is defined as in equation (13).

$$
s(t)=\dot{e}+\lambda e
$$

where $s(t)$ is defined as a PD-type sliding surface function, $\lambda$ is a positive constant value and the error is defined as $e=T_{r}-T$; here $T_{r}$ is the reference temperature and $T$ is the measured temperature value of the system. For a first-order system a fractional-order sliding surface can be described as follow.

$$
s(t)={ }_{a} D_{t}^{p} e+\lambda e
$$

The general sliding mode control law can be described as the following form.

$$
u(t)=u_{e q}(t)+u_{r}(t)
$$

where $u_{e q}$ and $u_{r}$ represent the equivalent control and reaching control laws, respectively. While the system is on the sliding surface, only the equivalent control is active. Therefore, the equivalent control term can be obtained while $\dot{s}(t)=0$ is valid. From equation (14), $\dot{s}$ is determined as given below. $\dot{s}(t)={ }_{a} D_{t}^{1+p} e+\lambda \dot{e}={ }_{a} D_{t}^{1+p} e+\lambda\left(\dot{T}_{r}-\dot{T}\right)$

where $\dot{T}=\hat{f}+\hat{g} u$ when the equivalent control is valid. In order to obtain the $u_{e q}(t)$, the lumped uncertainty term is assumed $\gamma=0$ in equation (8) and this yields as $\dot{T}=\hat{f}+\hat{g} u$. By substituting $\dot{T}=\hat{f}+\hat{g} u$ into equation (16), the $u_{e q}$ control becomes concrete as given below.

$u_{e q}(t)=\hat{g}^{-1}\left(\lambda^{-1}{ }_{a} D_{t}^{1+p}+\dot{T}_{r}-\hat{f}\right)$

Moreover, to achieve $u_{r}(t), \quad s \dot{s}<0$ must be satisfied. Thus, a positive definite Lyapunov function can be selected as given below.

$V=\frac{1}{2} s^{2}$

From (18), taking time derivative of the function,

$\dot{V}=s \dot{s}=-s P s<0$

where $P$ is a positive definite constant and the time derivative of $\dot{V}$ is achieved as a negative definite function. A solution can be offered as,

$s(\dot{s}+P s)=0$

and using equation (16), equation (21) can be obtained.

$$
\left({ }_{a} D_{t}^{1+p}+\lambda\left(\dot{T}_{r}-\dot{T}\right)+P s\right)=0
$$

By substituting $\dot{T}=\hat{f}+\hat{g} u$ into equation (21),

$$
\left({ }_{a} D_{t}^{1+p} e+\lambda\left(\dot{T}_{r}-\hat{f}-\hat{g} u\right)+P s\right)=0
$$

and if $u$ is withdrawn from the equation (22) clearly,

$$
u(t)=\hat{g}^{-1}\left[\left(\lambda^{-1}{ }_{a} D_{t}^{1+p} e+\dot{T}_{r}-\hat{f}\right)+\lambda^{-1} P\left({ }_{a} D_{t}^{p} e+\lambda e\right)\right]
$$


is obtained. From equation (23), the control signal without adaptation part can be derived as given below.

$$
\begin{aligned}
u(t)= & \underbrace{\hat{g}^{-1}\left(\lambda^{-1}{ }_{a} D_{t}^{1+p} e+\dot{T}_{r}-\hat{f}\right)}_{u_{e q}(t)} \\
& +\underbrace{\hat{g}^{-1}\left(\lambda^{-1} P\left({ }_{a} D_{t}^{p} e+\lambda e\right)\right)}_{u_{r}(t)}
\end{aligned}
$$

On the other hand, the following control law is taken into account in this paper to compensate uncertainties.

$$
u(t)=u_{e q}(t)+u_{r}(t)+u_{a}(t)
$$

where $u_{a}(t)$ is adaptive control term considered as a compensator to overcome the disturbances and parameter uncertainties and is defined based on the estimated disturbance $\hat{\gamma}$ (Zeinali and Khajepour, 2010).

$u_{a}(t)=-\hat{g}^{-1} \hat{\gamma}$

As a result, the whole control law is defined and used in this paper as in equation (27).

$$
\begin{aligned}
u(t)= & \hat{g}^{-1}\left(\left(\lambda^{-1}{ }_{a} D_{t}^{1+p} e+\dot{T}_{r}-\hat{f}\right)\right. \\
& \left.+\lambda^{-1} P\left({ }_{a} D_{t}^{p} e+\lambda e\right)-\hat{\gamma}\right)
\end{aligned}
$$

\subsubsection{Stability and robustness analysis}

The robustness and stability analysis of the system are provided by means of a Lyapunov function as given below (Zeinali and Khajepour, 2010).

$$
V=\frac{1}{2}\left(s^{2}+\Gamma^{-1} \tilde{\gamma}^{2}\right)
$$

where $\Gamma$ is a scalar positive constant and $\tilde{\gamma}$ is the estimation error that is defined as,

$$
\tilde{\gamma}=\hat{\gamma}-\gamma
$$

where $\hat{\gamma}$ is the estimated and $\gamma$ is the unknown values (Zeinali and Khajepour, 2010). The derivative of Lyapunov function is achieved as in equation (30).

$\dot{V}=s \dot{s}+\Gamma^{-1} \tilde{\gamma} \dot{\gamma}$

Using equations (16) and (29), equation (30) can be rewritten as the following form.

$\dot{V}=s\left({ }_{a} D_{t}^{1+p} e+\lambda\left(\dot{T}_{r}-\hat{f}-\hat{g} u-\gamma\right)\right)+\Gamma^{-1} \tilde{\gamma}(\dot{\hat{\gamma}}-\dot{\gamma})$

Rearranging equation (31) using equations (8) and (27), equation (32) can be obtained clearly.

$$
\begin{aligned}
\dot{V}= & s\left({ }_{a} D_{t}^{1+p} e+\lambda\left(\dot{T}_{r}-\hat{f}-\lambda^{-1}{ }_{a} D_{t}^{1+p} e-\dot{T}_{r}+\hat{f}\right.\right. \\
& \left.\left.-\lambda^{-1} P\left({ }_{a} D_{t}^{p} e+\lambda e\right)+\hat{\gamma}-\gamma\right)\right)+\Gamma^{-1} \tilde{\gamma}(\dot{\hat{\gamma}}-\dot{\gamma})
\end{aligned}
$$

If the update law is chosen as,

$\dot{\hat{\gamma}}=-\lambda \Gamma s$

and by substituting equation (33) into equation (32), equation (34) is achieved.

$\dot{V}=-s P s+\lambda s \tilde{\gamma}+\Gamma^{-1} \tilde{\gamma}(-\Gamma s \lambda-\dot{\gamma})$

For final $\dot{V}$ expression,

$\dot{V}=-s P s-\Gamma^{-1} \tilde{\gamma} \dot{\gamma}$

which satisfies $\dot{V}<0$ under the assumption of given below.

$P\left|s^{2}>\Gamma^{-1}\right| \tilde{\gamma} \| \dot{\gamma} \mid$

where $P$ and $\Gamma$ is the design parameters for nonlinear uncertain systems with fast timevarying uncertainty (Zeinali and Khajepour, 2010). Moreover, in this paper, three SMC based controllers have been tested. Therefore, to derive the remaining two controllers called 
as the ASMC and SMC, an integer-order sliding surface can be defined as given below.

$s(t)=\dot{e}+\lambda e$

Also, the ASMC method has been derived as the same control algorithm as in AFOSMC expect for only one difference that is available on defining the sliding surface. Thus, the control signal can be written as in equation (27).

$$
u(t)=\hat{g}^{-1}\left[\left(\lambda^{-1} \ddot{e}+\dot{T}_{r}-\hat{f}\right)+\lambda^{-1} P(e+\lambda e)-\hat{\gamma}\right]
$$

Besides, due to having no adaptation law, the general SMC can be derived as given below.

$$
u(t)=\hat{g}^{-1}\left[\left(\lambda^{-1} \ddot{e}+\dot{T}_{r}-\hat{f}\right)+\lambda^{-1} P(e+\lambda e)\right\rfloor
$$

Also, the control structure used in the simulation study is given in Figure 2.

\section{Results and Discussion}

For all controllers used in this study, step + sinusoidal and step + square references were preferred and applied for the heat flow system. Also, for initial value for $\hat{\gamma}$ is chosen as 22 for both controllers.

First of all, step + sinusoidal reference is given to the system in order to test the response of the controllers to the references that contain slow change over time. In Figure 3, it can be seen that the AFOSMC has a better rise time and settling time than other controllers in the step part of the given reference. Then, when the sinusoidal component of the given reference is applied, it is seen that the AFOSMC responds quickly to the change in the reference and adapts itself faster than other controllers. In Figure 4, although the error levels of all controllers seems to be almost the same size, it is seen that the tracking error of the temperature profile of the proposed controller is actually less than ASMC and SMC. In addition, when Figure 5 is examined, it is seen that all controllers produce control command of similar form and size, but the proposed AFOSMC produces better control command in order to follow the reference.

Figure 6 shows the results of three controllers for step + square reference. The step reference tracking performances of the controllers are similar to that of Figure 3, since the step part of the reference signal did not change. On the other hand, when the square part of the reference signal is applied, it is seen that the AFOSMC has the same rise time as the ASMC, but AFOSMC has a smaller settling time and overshoot.

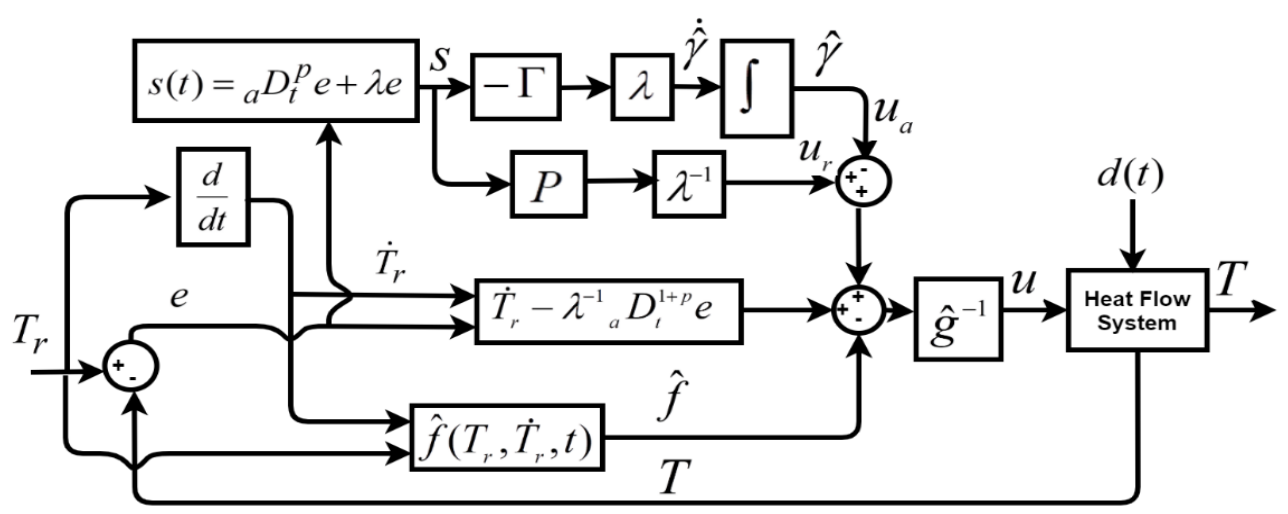

Figure 2. The control block diagram of heat flow system 


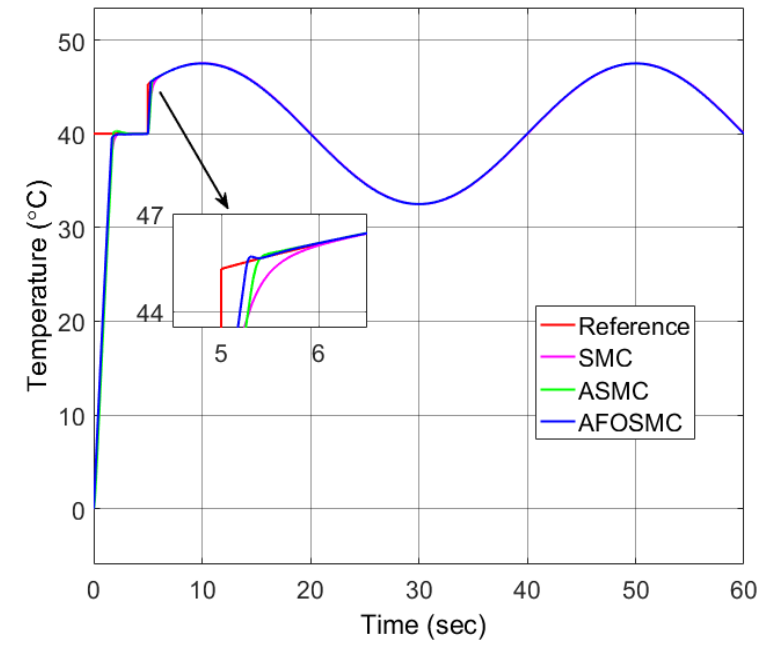

Figure 3. The simulation results of all controllers under step + sinusoidal reference signal

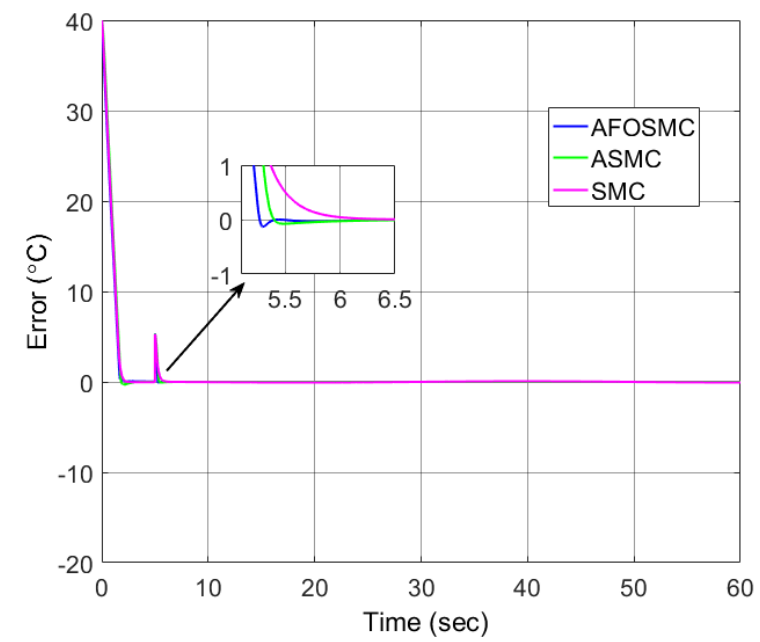

Figure 4. The temperature error levels of all controllers

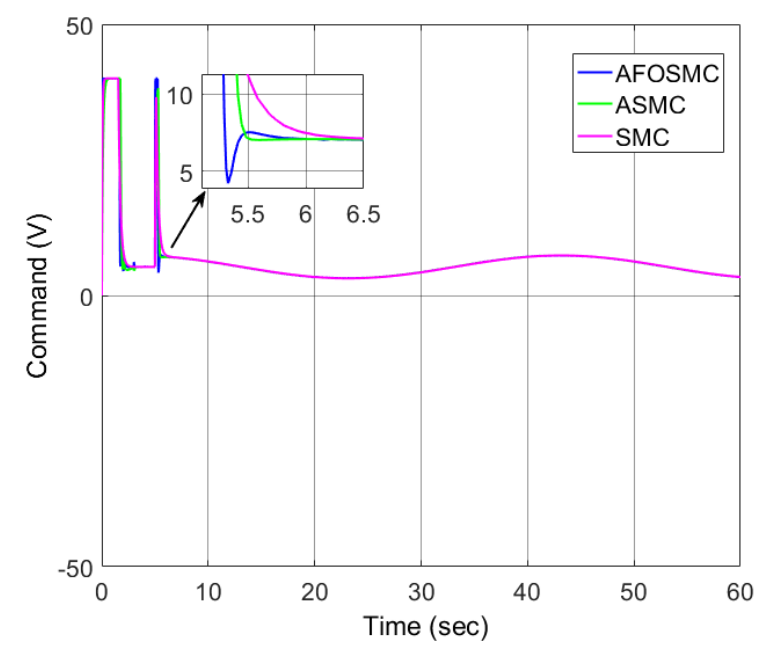

Figure 5. The control signals of all controllers

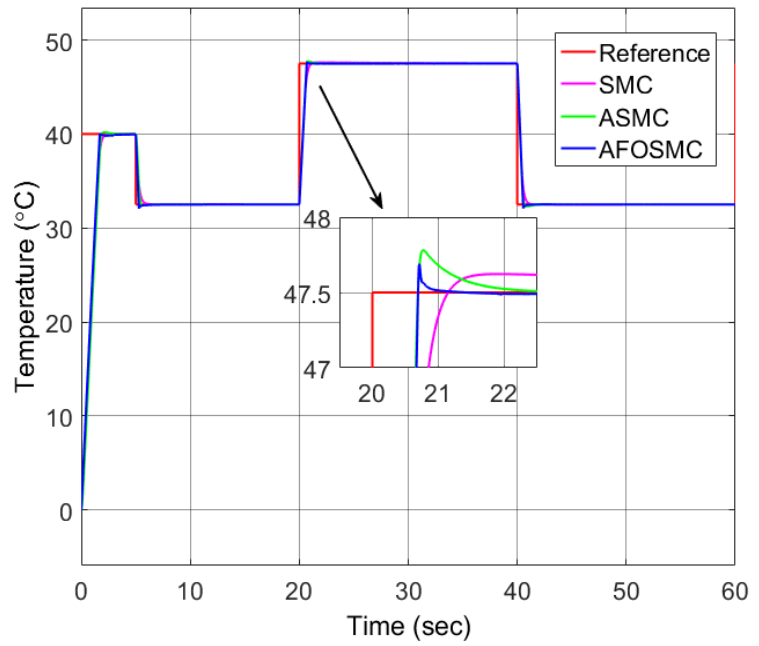

Figure 6. The simulation results of all controllers under step + square reference signal

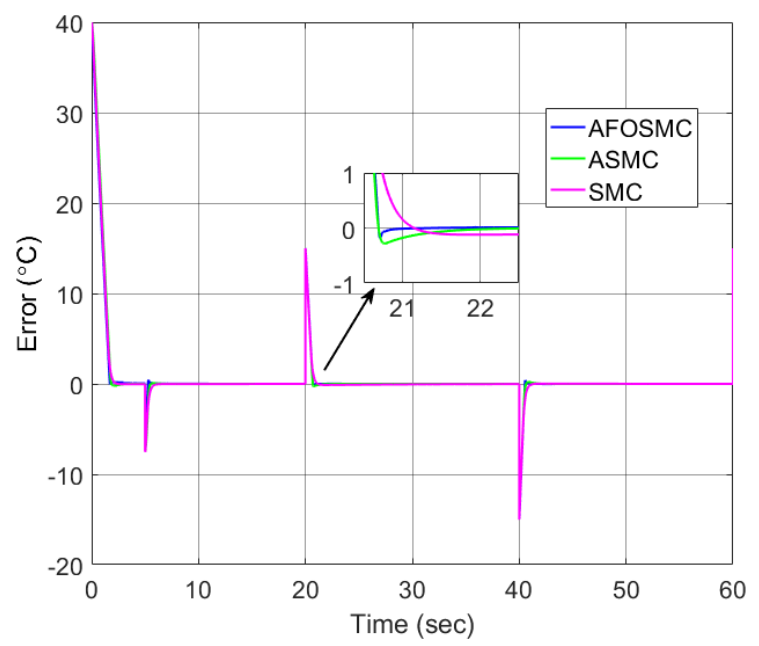

Figure 7. The temperature error levels of all controllers

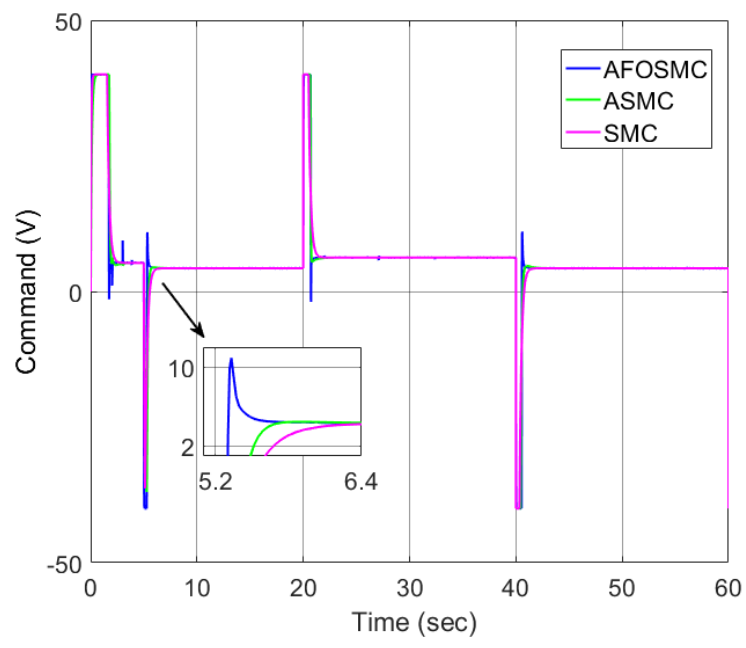

Figure 8. The control signals of all controllers 
Also, it is seen that the rise time and settling times of SMC is higher than the other two controllers, but the amount of overshoot is lower. It can be seen from Figure 7 that the SMC has a steady state error, but the AFOSMC follows the square reference signal with less error than the ASCM. In Figure 8, the control commands generated by controllers are presented.

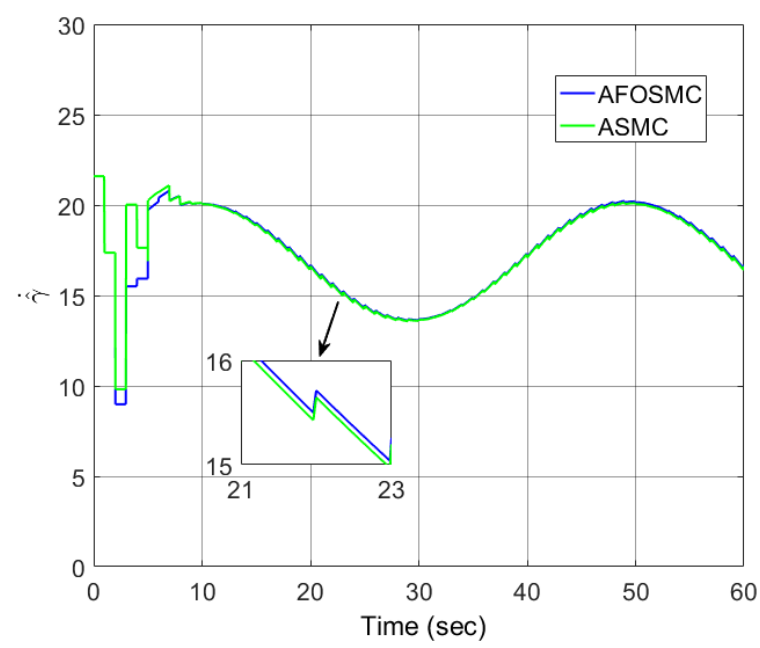

Figure 9. The adaptation gain signals for AFOSMC and ASMC under step + sinusoidal signal

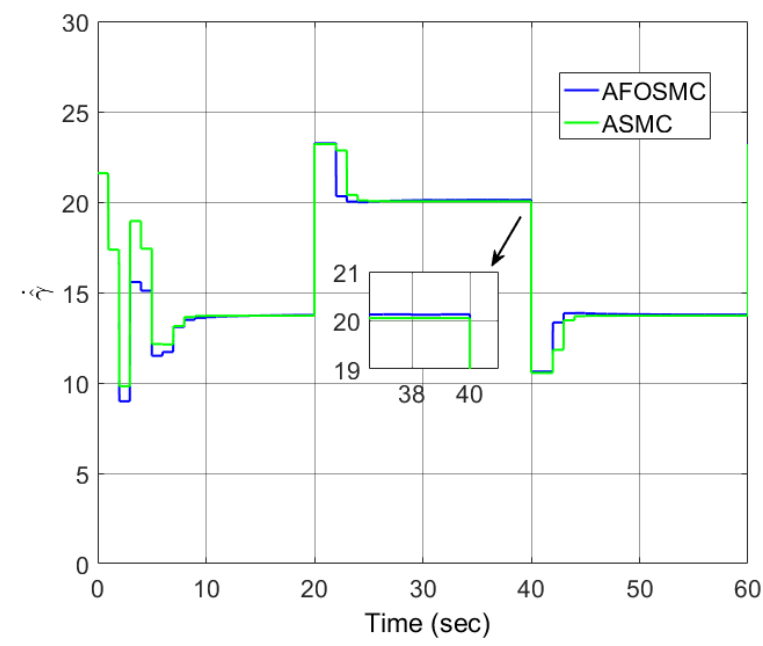

Figure 10. The adaptation gain signals for AFOSMC and ASMC under step + square signal

Although, the AFOSMC produced bigger control command than the other two controllers to perform reference tracking at the sudden change points of the square reference signal, and therefore following the reference signal better.

Figure 9 resents the adaptation gain changes with respect to time for AFOSMC and ASMC. As seen from the figure, during the step part of the reference signal, the AFOSMC produced the required adaptation parameter larger and smoother than that of ASMC. Also, for the sinusoidal part of the reference signal, both controllers have adaptation gain parameters of similar size and form. As seen in Figure 10, the AFOSMC produced a larger and more similar adaptation gain to the square reference signal than the ASMC at the points where the square signal suddenly changes. Therefore, the square reference signal followed better.

\section{Conclusions}

In this paper, temperature profile tracking performance of SMC, ASMC and AFOSMC are tested for step + sinusoidal and step + square references in simulation environment. The simulation results have showed that the AFOSMC has better results than the other controllers in terms of having less tracking error level, giving fast response to sudden changes and having less rise and settling time as well as less overshoot. In the following studies, it is planned to test the proposed controller with more robustness in a real time experiment on HFS.

\section{References}

Agrawal, R. A., Pandelidis, I.O., \& Pecht, M., (1987). "Injection-molding process control- A rewiev", Polym. Eng. Sci., 27(18), 1345-1357. https://doi.org/10.1002/pen.760271802 
Omatu, S., Yusof, R., Sinohara, K., \& Hotta, M., (1992). "Temperature control for heating cylinder by multivariable STC", Trans. Syst. Contr. Inform. Eng., 5(3), 102110.

Seaman, M., Desrochers, A.-A., \& List, G.F., (1994). "Multiobjective optimization of a plastic injection molding process", IEEE Trans. Contr. Syst. Technology, 2(3), 157168. DOI: $10.1109 / 87.317974$

Taur, J.-S., Tao, C.-W., \& Tsai, C.-C., (1995). "Temperature control of a plastic extrusion barrel using PID fuzzy controllers", Proceedings IEEE Conference on Industrial Automation and Control: Emerging Technology Applications. DOI: 10.1109/IACET.1995.527590

Lin, C.-T., Juang, C.-F., \& Li, C.-P. (1999). "Temperature control with a neural fuzzy inference network", Systems, Man, and Cybernetics, Part C: Applications and Reviews, IEEE Transactions on. 29(3), 440-451. DOI: $10.1109 / 5326.777078$

Petráš, I., \& Vinagre, B.-M., (2002). "Practical application of digital fractionalorder controller to temperature control", Acta Montanistica Slovaca, 7(2), 131-13.

Juang, C.-F., \& Chen, J.-S (2003). “A recurrent neural fuzzy network controller for a temperature control system", The 12th IEEE International Conference on Fuzzy Systems, FUZZ'03, St Louis ,USA. DOI: 10.1109/FUZZ.2003.1209398

Ramos, H.-M.-S.-G., Assuncao, F., Ribeiro, A.-L., \& Ramos, P.-M., (2004). "A low-cost temperature controlled system to test and characterize sensors", 7th AFRICON Conference in Africa, Gaborone, Botswana. DOI: 10.1109/AFRICON.2004.1406715

Can, K., \& Başçi, A., (2017). "Temperature Control of A Heat Flow Experimental Setup via Fractional-Order PI Controller", 2nd
International Conference on Advanced Engineering Technologies (ICADET 2017), Bayburt, Turkey.

Ahn, H.-Y. Bhambhani, V., \& Chen, Y.-Q., (2008). "Fractional-order integral and derivative controller design for temperature profile control", 2008 Chinese Control and Decision Conference, Shandong, China. DOI: $10.1109 / C C D C .2008 .4598234$

Jain, M., Rani, A., Pachauri, N., Singh, V., \& Mittal, A.-P., (2019). "Design of fractional order 2-DOF PI controller for real-time control of heat flow experiment", Engineering Science and Technology, an International Journal, 22(1), 215-228. https://doi.org/10.1016/j.jestch.2018.07.00 2

Young, K.-D., Utkin, V.-I., \& Özgüner, Ü, (1999). "A control engineer's guide to sliding mode control", IEEE Trans. Control Syst. Technol., 7(3), 328-342.

Ioannou, P., \& Sun, J., (2012). "Robust adaptive control", Courier Corporation.

Åströ, K.-J., \& Wittenmark, W., (2013). “Adaptive control”, Courier Corporation.

Jaemin, B., Jin, M., \& Han, S., (2016). “A new adaptive sliding-mode control scheme for application to robot manipulators", IEEE Transactions on Industrial Electronics 63(6), 3628-3637.

DOI: $10.1109 /$ TIE.2016.2522386

Liao, Y.-W., Pan, S., Borrelli, F., \& Hedrick, J.-K., (2018). "Adaptive sliding mode control without knowledge of uncertainty bounds", 2018 Annual American Control Conference (ACC), Milwaukee, WI, USA. DOI:10.23919/ACC.2018.8431124

Heat Flow Experiment Setup https://www.quanser.com/products/heatflow-experiment/ 
Gutman. S., (1979). "Uncertain Dynamical Systems: A Lyapunov Min-Max Approach", IEEE Trans. Autom. Control, 24(3), 437-443.

DOI: 10.1109/TAC.1979.1102073

Vinagre, B.-M. Podlubny, I., Hernandez, A., \& Feliu, V. (2000). "Some approximations of fractional order operators used in control theory and applications", Fractional Calculus and Applied Analysis, 3(3), 231-248.
Podlubny, I., (1999). "Fractional differential equations", New York: Academic Press.

Zeinali, M., \& A., Khajepour, (2010). "Height control in laser cladding using adaptive sliding mode technique: theory and experiment", Journal of Manufacturing Science and Engineering, 132(4). https://doi.org/10.1115/1.4002023 